\title{
PROTECTIVE ROLES OF NOVEL THIOSEMICARBAZONE DERIVATIVES ON HEPATOTOXICITY AND NEPHROTOXICITY INDUCED BY CADMIUM CHLORIDE IN RATS
}

\author{
ABEER A. EL-SISI ${ }^{1}$, SOHAIR RAMADAN FAHMY ${ }^{2}$, MOHAMED ALI EL-DESOUKY ${ }^{1}$, \\ OSAMA EL-TAWIL ${ }^{3}$, AYMAN SABER MOHAMED ${ }^{2}$, and AHMED A. EL-SHERIF ${ }^{1}$ \\ ${ }^{1}$ Department of Chemistry, Faculty of Science, \\ ${ }^{2}$ Department of Zoology, Faculty of Science, \\ ${ }^{3}$ Toxicology and Forensic Medicine Department, Faculty of Veterinary Medicine, Cairo University, \\ 12613, Cairo, Egypt
}

\begin{abstract}
The present study aims to investigate for the first time the possible therapeutic effect of four novel synthesized thiosemicarbazones (TSCs) compounds against cadmium toxicity in rats. The experimental animals were assigned into two main groups, control and cadmium chloride $\left(\mathrm{CdCl}_{2}\right)(50 \mathrm{mg} / \mathrm{kg}$ body weight) treated group. $\mathrm{CdCl}_{2}$ treated group then subdivided into five subgroups, vehicle subgroup, TSC1, TSC2, TSC3 and TSC4 treated subgroups. Cd administration resulted in a significant increase in aspartate aminotransferase (AST), alanine transaminase (ALT), and alkaline phosphatase (ALP), creatinine, urea, and uric acid levels. Cd intoxication significantly increased the level of the liver and kidney malondialdehyde (MDA) and decreased levels of reduced glutathione (GSH) and catalase (CAT) in the liver and kidney tissues. Cotreatment with the four thiosemicarbazones derivative compounds significantly reversed the hepatorenal alterations induced following cadmium administration. It can be concluded from the aforementioned investigation that the synthesized TSCs derivatives might be acting through two main mechanisms, the $1^{\text {st }}$ one is antioxidant and the $2^{\text {nd }}$ one is chelating therapy.
\end{abstract}

Keywords: cadmium, thiosemicarbazones, liver function, kidney function, oxidative stress

Contamination of food and feedstuffs with heavy metals represent a major health problem in animals and human (1). Cadmium (Cd) is a common food contaminant and considered one of the most widely spread environmental pollutants (2). Besides, $\mathrm{Cd}$ is a bio-hazard with no physiological function in the human body (3). $\mathrm{Cd}$ is one of the most extensively distributed toxicants due to its excessive use in modern lifestyles (4). Owing to increasing use in plating, pigments, metal coating, plastic manufacturers, and nickel-Cd batteries, it is likely that through both deliberate application and accidental release, $\mathrm{Cd}$ will find its way into aquatic, terrestrial, and atmospheric environments (5). Emission of Cd from industrial activities, agricultural practices using contaminated phosphate fertilizers and sewage sludge, and also tobacco smoke leads to environmental pollution (6).

The potential impact of Cd toxicity has attracted special attention due to its long half-life which leads to its accumulation in living tissues for long periods (3). Elucidating the possible correlation between environmental pollutants and stress-related disease conditions in animals needs a great effort. There has been a wealth of studies that describe oxidative stress (OXS) during Cd toxicity, with evidence of reactive oxygen species (ROS) production (7). The liver and kidney are the most targeted organs for Cd toxicity (2). Hepatotoxicity is the main reason for $\mathrm{Cd}$ acute lethality consequent to $\mathrm{Cd}$ transportation (8). $\mathrm{Cd}$ is a well-studied nephrotoxic metal element and its toxicity is represented through the structural damage of kidneys and changes in the excretory function (7).

The predicted increase in the incidence of $\mathrm{Cd}$ toxicity justifies a search for opportunities to prevent its adverse effects. For the therapeutic strategies of cadmium toxicity, it is important to find a safe compound that can block its injuries. Chelation therapy is the most commonly used therapeutic strategy for heavy metal poisoning. Chelation therapy plays an important role in modern medicine and pharmacology and has been the mainstay to remove toxic metals from human organs and tissue (9). Unfortunately, the

* Corresponding author: e-mail: ayman81125@hotmail.com 
current pharmacological therapy used for Cd toxicity has serious deleterious effects. Also, to our knowledge, there are no approved chelation therapies for Cd toxicity for clinical use. A Schiff-base compound like hydrazones and thiosemicarbazones (TSCs) are widely used in medicinal chemistry due to their wide biological activities (10). The wide spectrum of biological properties shown by TSCs derivatives attracts the researchers' interest (11). The development of safe and efficient strategies against $\mathrm{Cd}$ toxicity is, therefore, an area of ongoing research. Thereby, the present study was designed to investigate the possible therapeutic effect of four novel synthesized TSCs compounds against $\mathrm{Cd}$ toxicity in rats. The present study extended to elucidate the mechanism of the studied TSCs derivatives in Cd detoxification.

\section{MATERIAL}

\section{Material}

Thiosemicarbazone (TSCs) derivatives (Figure 1) were synthesized by Dr. Ahmed El-Sheerf, Chemistry Department, Faculty of Science, Cairo University. Cadmium chloride $\left(\mathrm{CdCl}_{2}\right)$ was dissolved in distilled water. The selected dose of $\mathrm{CdCl}_{2}$ was selected on the basis of previous studies $(12,13)$. Cadmium chloride was administered orally because it is the main mode of exposure to cadmium in humans and animals.



(E)-2-((E)1-(2-(p-tolyl) hydrazono) propan-2-ylidene hydrazine-1-carbothioamide

\section{In vitro antioxidant}

The free radical scavenging activities of each synthesized TSC derivative were analyzed by the 1,1diphenyl-2-picryl hydrazyl (DPPH) assay (14). The absorbance of sample, blank sample, and control was measured at $517 \mathrm{~nm}$, after $30 \mathrm{~min}$ incubation in the dark at room temperature, using Thermo Scientific Evolution 201 UV-Visible Spectrophotometer. The experiment was done in triplicates. The percentage of antioxidant activity was calculated as follows:

Antioxidant activity, AA $(\%)=100-[\{($ Abs sample - Abs blank $) \times 100\} /$ Abs control] .

\section{Experimental animals}

Male conventional Wistar rats (outbred) strain, weighing 150-160+5 g were used (National Research Center, Dokki, Egypt). During the period of the acclimation (7 days) and the experimental periods, the rats were fed standard rodent food pellets (Agricultural-Industrial Integration Company, Giza, Egypt) ad libitum. Tap water was also provided ad $l i$ bitum and renewed every day. Rats were grouped and housed in polyacrylic cages (six animals per cage) and supplied with sawdust, bedding materials, and Kleenex tissues as nesting material plus two wooden cubes. The room was maintained at a constant temperature $\left(22^{\circ} \mathrm{C}-25^{\circ} \mathrm{C}\right)$ and $12: 12 \mathrm{~h}$ light : dark. The room also schedules with the white light on<smiles>CNC(=S)N/N=C/C(C)=N/Nc1ccc(C)cc1</smiles>

(E)-N-methyl-2-((E)-1-(2-(p-tolyl) hydrazono) propan2-ylidene)hydrazine-1-carbothioamide<smiles>CCNC(=S)N/N=C/C(C)=C\Nc1ccc(C)cc1</smiles>

(E)-N-ethyl-2-((E)-1-(2-(p-tolyl)hydrazono)propan2-ylidene)hydrazine-1 carbothioamide

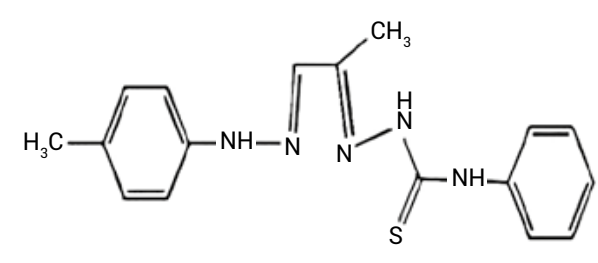

(E)-N-phenyl-2-((E)-1-(2-(p-tolyl)hydrazono)propan2-ylidene)hydrazine-1 carbothioamide 
between 02:00 and 14:00 h. Experimental protocols and procedures used in this study were approved by the Cairo University, Institutional Animal Care and Use Committee (CU-IACUC) (Egypt), (approval no. $\mathrm{Cu} / \mathrm{F} / \mathrm{I} / 86 / 18)$.

\section{Estimation of LD50 based on in vitro IC50 value}

To reduce the number of animals used in acute oral toxicity testing, cytotoxicity data $\left(\mathrm{IC}_{50}\right)$ can be used to determine the starting dose for in vivo testing by applying the standard regression between $\mathrm{IC}_{50}$ and acute oral $\mathrm{LD}_{50}$ values in the Register of Cytotoxicity (RC) (Spielmann et al., 1999; ICCVAM, 2006). As the molecular weight of the synthesized TSCs compounds is identified, thereby the estimated $\mathrm{LD}_{50}$ was determined using the following equation:

$$
\log \left(\mathrm{LD}_{50}\right)=0.435 \times \log \left(\mathrm{IC}_{50}\right)+0.625
$$

The $\mathrm{LD}_{50}$ values of rats were estimated from the $\mathrm{IC}_{50}$ values obtained from the in vitro cytotoxic NRU assay on HepG2 (unpublished data) because these cells have the highest cytotoxic sensitivity to the synthesized TSCs compounds (15).

\section{Acute toxicity study}

Acute oral toxicity was evaluated by following Organization of Economic Co-operation and Development (OECD) guidelines 423- Fixed-Dose Procedure (FDP), where the concentration range is 5, 50,300 , and $2000 \mathrm{mg} / \mathrm{kg}$ (upper limit of $2000 \mathrm{mg} / \mathrm{kg}$ ) (OECD, 2001). The estimated $\mathrm{LD}_{50}$ relevant to each studied compound was used as the starting dose for FDP. Observation of Wellness parameters of animals were observed continuously during the first $30 \mathrm{~min}$ and the first 4 hours after dosing. Animals were also observed for the next 24 hours and then daily thereafter, for 14 days. All observations were systematically recorded with individual records being maintained for each animal. Changes in wellness parameters were compared with that of control animals.

\section{Experimental design}

Thirty-six male Wistar rats were assigned into two main groups, control (6 rats/group) and $\mathrm{CdCl}_{2}$ treated group (30 rats/group). Animals in $\mathrm{CdCl}_{2}$ treated group was administered $\mathrm{CdCl}_{2}$ at a dosage of $50 \mathrm{mg} / \mathrm{kg}$ body weight once every two days and concurrently treated with the synthesized TSC derivative for 21 consecutive. This group was divided into 5 subgroups (6 rats/ subgroup) as follow:

- Subgroup I (Vehicle group): Rats of this subgroup administered dimethyl sulfoxide (DMSO) orally.
- Subgroup II $\left(\mathrm{CdCl}_{2}+\mathrm{TSC}_{1}\right)$ : Animals of this subgroup were treated orally with $\mathrm{CdCl}_{2}$ and $\mathrm{TSC}_{1}(200 \mathrm{mg} / \mathrm{kg}$ body weight).

- Subgroup III $\left(\mathrm{CdCl}_{2}+\mathrm{TSC}_{2}\right)$ : Animals of this subgroup were treated orally with $\mathrm{CdCl}_{2}$ and $\mathrm{TSC}_{2}(200 \mathrm{mg} / \mathrm{kg}$ body weight).

- Subgroup IV $\left(\mathrm{CdCl}_{2}+\mathrm{TSC}_{3}\right)$ : Animals of this subgroup were treated orally with $\mathrm{CdCl}_{2}$ and $\mathrm{TSC}_{3}(200 \mathrm{mg} / \mathrm{kg}$ body weight $)$.

- Subgroup $\boldsymbol{V}\left(\mathrm{CdCl}_{2}+\mathrm{TSC}_{4}\right)$ : Animals of this subgroup were treated orally with $\mathrm{CdCl}_{2}$ and $\mathrm{TSC}_{4}(30 \mathrm{mg} / \mathrm{kg}$ body weight$)$.

\section{Animals handling and sample preparation}

After 21 days, animals were euthanized under deep anesthesia with sodium pentobarbital (100 mg/ $\mathrm{kg}$ body weight). Blood samples were collected by cardiac puncture in EDTA tubes for hematological and biochemical parameters. After the hematological measurement, blood samples were centrifuged at $3000 \mathrm{rpm}$ for $20 \mathrm{~min}$. Plasma samples were stored at $-20^{\circ} \mathrm{C}$ until used for biochemical assays. The liver and kidney were dissected out immediately and divided into two parts; the first part was suspended in $10 \%$ formal saline for fixation and preparation for histological processing. While the second part is stored at $-80^{\circ} \mathrm{C}$ for biochemical analysis. Liver and kidney tissues were homogenized $(10 \% \mathrm{w} / \mathrm{v})$ in ice-cold $0.1 \mathrm{M}$ Tris-HCl buffer ( $\mathrm{pH} 7.4)$. The homogenate was centrifuged at $3000 \mathrm{rpm}$ for $15 \mathrm{~min}$ at $4^{\circ} \mathrm{C}$ and the resultant supernatant was used for biochemical analysis. Liver and kidney slices were fixed in $10 \%$ formal saline and embedded in paraffin wax blocks. Sections of $5 \mu \mathrm{m}$ thick were stained with hematoxylin and eosin (H\&E) then examined under a light microscope for determination of pathological changes.

\section{Hematological parameters}

A complete blood count (CBC) was performed on the blood sample using the Coulter- Counter technique that was earlier described by Coulter (16). Blood samples were placed in Swelab's fully automatic auto- counter, model AC920EO+ (Cape Town, South Africa).

\section{Biochemical analysis}

The appropriate kits (Bio-Diagnostic, Dokki, Giza, Egypt) were used for the determination of liver enzyme parameters aspartate aminotransferase (AST), alanine transaminase (ALT), and alkaline phosphatase (ALP). The same kits were used to determine the kidney function parameters as creatinine, urea; and uric acid. 


\section{Oxidative stress parameters}

The appropriate kits (Bio-Diagnostic kits, BioDiagnostic, Dokki, Giza, Egypt) were used for the determination of malondialdehyde (MDA) (17), reduced glutathione (GSH) (18), and catalase (CAT) were detected according to the method described by Aebi (19).

\section{Statistical analysis}

Values were expressed as means $\pm \mathrm{SE}$. To evaluate differences between the groups studied, a oneway analysis of variance (ANOVA) with Duncan post hoc test was used to compare the group means, and $\mathrm{P}<0.05$ was considered statistically significant. SPSS, for Windows (version 15.0) was used for the statistical analysis.

\section{RESULTS AND DISCUSSION}

\section{In vitro antioxidant}

Cadmium is a toxic metal that promotes early oxidative stress (20). Chelation therapy is currently the primary treatment modality in the alleviation or prevention of Cd toxicity. Ethylenediaminetetraacetic acid (EDTA) (21) and Dimercaprol (22) are the most important chelating agents that have been used during $\mathrm{Cd}$ toxicity. However, the development of acute renal failure subsequent to EDTA and Dimercaprol administration during $\mathrm{Cd}$ toxicity is the main obstacle for their use $(21,23)$. Therefore, the development of novel chelating agents would play a key role in the treatment of $\mathrm{Cd}$ toxicity. For the therapeutic strategies of hepatorenal injury following $\mathrm{Cd}$ toxicity in living organisms, it is important to find a complementary antioxidant compound that is able to block this injury. The present study proved the potential therapeutic role of the four novel thiosemicarbazones (TSCs) derivatives against $\mathrm{Cd}$ hepatotoxicity and nephrotoxicity in rats. The results of the DPPH scavenging activity of the four synthesized TSC derivatives are shown in Figure 2. The radical scavenging activities were estimated by comparing the percentage of inhibition of DPPH radical by the four synthesized TSC derivatives. The present results showed that $\mathrm{TSC}_{2}$ with methyl substitution showed the least DPPH scavenging activity as compared to the remaining derivatives. Figure 1 also showed that $\mathrm{TSC}_{3}$ and $\mathrm{TSC}_{4}$ with ethyl and phenyl substitutions showed the same antioxidant activity.

\section{Estimated LD50 based on in Vitro HepG2 and MCF-7 Cell Lines}

The estimated $\mathrm{LD}_{50}$ was determined according to ICCVAM (2006) using the following equation: $\log \left(\mathrm{LD}_{50}\right)=0.435 \times \log \left(\mathrm{IC}_{50}\right)+0.625$. Data recorded in Table 1 , showed that the estimated $\mathrm{LD}_{50}$ for the studied four synthesized TSCs compounds using the $\mathrm{IC}_{50}$ of the HepG2 cell lines were 168.32, 131.5, 83.65 , and 45.9 respectively. Regarding the estimation of $\mathrm{LD}_{50}$ for the studied four synthesized TSCs compounds using the $\mathrm{IC}_{50}$ of the using MCF-7 cell Lines, data recorded in Table 2 showed that $\mathrm{LD}_{50}$ for the studied four synthesized TSCs compounds were $223.9,260,314.39$, and 195.83 respectively.

\section{Acute toxicity of synthesized thiosemicarbazone compounds}

Results indicated that the TSCs compound number I. II and III up to a dosage of $2000 \mathrm{mg} / \mathrm{kg}$; p.o. did not produce any mortality. However, TSCs compound number IV has been found toxic at $2000 \mathrm{mg} / \mathrm{kg}$ body



50

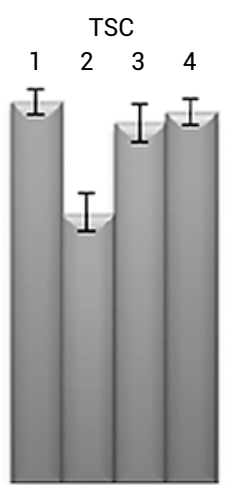

100

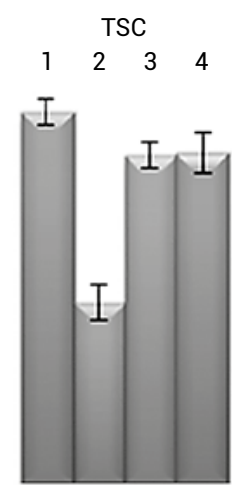

150

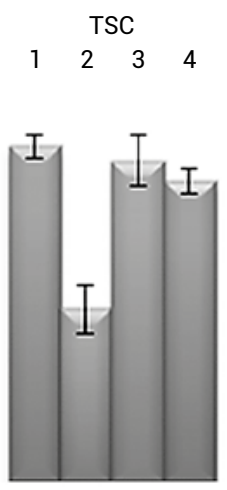

200

Concentration $(\mu \mathrm{g} / \mathrm{ml})$

Figure 2. Antioxidant activity of the four synthesized TSC derivatives. Each vertical column represents the mean $\pm \mathrm{SEM}$ change of three replications. 
Table 1. Estimation of $\mathrm{LD}_{50}$ for the synthesized thiosemicarbazone compounds based on IC50 of the HepG2 Cell Lines.

\begin{tabular}{|c|c|c|c|c|}
\hline Compound & Formula & M.wt & $\mathrm{IC}_{50}(\mathrm{ug} / \mathrm{mL})$ & Estimated $\mathrm{LD}_{50}$ \\
\hline $\mathrm{TSC}_{1}$ & $\mathrm{C}_{11} \mathrm{H}_{15} \mathrm{~N}_{5} \mathrm{~S}$ & 249 & 29.4 & 168.32 \\
\hline $\mathrm{TSC}_{2}$ & $\mathrm{C}_{12} \mathrm{H}_{17} \mathrm{~N}_{5} \mathrm{~S}$ & 263 & 72 & 131.5 \\
\hline $\mathrm{TSC}_{3}$ & $\mathrm{C}_{13} \mathrm{H}_{19} \mathrm{~N}_{5} \mathrm{~S}$ & 277 & 46 & 83.65 \\
\hline $\mathrm{TSC}_{4}$ & $\mathrm{C}_{17} \mathrm{H}_{19} \mathrm{~N}_{5} \mathrm{~S}$ & 325 & 25 & 45.9 \\
\hline
\end{tabular}

Table 2. Estimation of $\mathrm{LD}_{50}$ for the synthesized thiosemicarbazone compounds based on IC50 of the MCF-7 Cell Lines.

\begin{tabular}{|c|c|c|c|c|}
\hline Compound & Formula & M.wt & $\mathrm{IC}_{50}(u g / m L)$ & Estimated $\mathrm{LD}_{50}$ \\
\hline $\mathrm{TSC}_{1}$ & $\mathrm{C}_{11} \mathrm{H}_{15} \mathrm{~N}_{5} \mathrm{~S}$ & 249 & 122 & 223.9 \\
\hline $\mathrm{TSC}_{2}$ & $\mathrm{C}_{12} \mathrm{H}_{17} \mathrm{~N}_{5} \mathrm{~S}$ & 263 & 142 & 260 \\
\hline $\mathrm{TSC}_{3}$ & $\mathrm{C}_{13} \mathrm{H}_{19} \mathrm{~N}_{5} \mathrm{~S}$ & 277 & 173 & 314.39 \\
\hline $\mathrm{TSC}_{4}$ & $\mathrm{C}_{17} \mathrm{H}_{19} \mathrm{~N}_{5} \mathrm{~S}$ & 325 & 107 & 195.83 \\
\hline
\end{tabular}

weight of experimental animals as in the first 4 hours of observation $2 / 3$ morbidity was observed and in the next 24 hours of observation mortality in the ratio 2/3 were found (Table 3 ). No significant changes were observed in body weight and wellness parameters used for evaluation of toxicity for TSCs compound number I, II, and III. Thereby, the $\mathrm{LD}_{50}$ value was found to be more than $2000 \mathrm{mg} / \mathrm{kg}$ body weight. For TSCs compound number IV, the LD50 value was found to be more than $300 \mathrm{mg} / \mathrm{kg}$ body weight but less than $2000 \mathrm{mg} / \mathrm{kg}$ body weight.

\section{Effect of the thiosemicarbazone derivatives on the different hematological parameters in Cd-intoxicated rats}

Data recorded in Table 4 indicated that $\mathrm{Cd}$ intoxication caused a significant increase $(\mathrm{P}<0.05)$ in WBCs count as compared to the control group. On

Table 3. Observation of Wellness parameters at 50,300, and $2000 \mathrm{mg} / \mathrm{kg}$ Body Weight for thiosemicarbazide compound number I, II, and III.

\begin{tabular}{|c|c|c|c|c|c|c|c|c|c|c|c|c|c|}
\hline \multirow{2}{*}{\multicolumn{2}{|c|}{ Observation }} & \multicolumn{2}{|c|}{$30 \min$} & \multicolumn{2}{|c|}{$4 \mathrm{~h}$} & \multicolumn{2}{|c|}{$4 \mathrm{~h}$} & \multicolumn{2}{|c|}{$8 \mathrm{~h}$} & \multicolumn{2}{|c|}{1 week } & \multicolumn{2}{|c|}{2 weeks } \\
\hline & & $\mathrm{C}$ & $\mathrm{T}$ & $\mathrm{C}$ & $\mathrm{T}$ & $\mathrm{C}$ & $\mathrm{T}$ & $\mathrm{C}$ & $\mathrm{T}$ & $\mathrm{C}$ & $\mathrm{T}$ & $\mathrm{C}$ & $\mathrm{T}$ \\
\hline \multicolumn{2}{|c|}{ Skin and Fur } & $\mathrm{N}$ & $\mathrm{N}$ & $\mathrm{N}$ & $\mathrm{N}$ & $\mathrm{N}$ & $\mathrm{N}$ & $\mathrm{N}$ & $\mathrm{N}$ & $\mathrm{N}$ & $\mathrm{N}$ & $\mathrm{N}$ & $\mathrm{N}$ \\
\hline \multicolumn{2}{|c|}{ Eyes } & $\mathrm{N}$ & $\mathrm{N}$ & $\mathrm{N}$ & $\mathrm{N}$ & $\mathrm{N}$ & $\mathrm{N}$ & $\mathrm{N}$ & $\mathrm{N}$ & $\mathrm{N}$ & $\mathrm{N}$ & $\mathrm{N}$ & $\mathrm{N}$ \\
\hline \multicolumn{2}{|c|}{ Mucous Membrane } & $\mathrm{N}$ & $\mathrm{N}$ & $\mathrm{N}$ & $\mathrm{N}$ & $\mathrm{N}$ & $\mathrm{N}$ & $\mathrm{N}$ & $\mathrm{N}$ & $\mathrm{N}$ & $\mathrm{N}$ & $\mathrm{N}$ & $\mathrm{N}$ \\
\hline \multicolumn{2}{|c|}{ Salivation } & A & $\mathrm{A}$ & $\mathrm{A}$ & $\mathrm{A}$ & A & $\mathrm{A}$ & $\mathrm{A}$ & $\mathrm{A}$ & $\mathrm{A}$ & $\mathrm{A}$ & $\mathrm{A}$ & $\mathrm{A}$ \\
\hline \multicolumn{2}{|c|}{ Lethargy } & A & $\mathrm{A}$ & A & $\mathrm{A}$ & A & A & A & $\mathrm{A}$ & $\mathrm{A}$ & $\mathrm{A}$ & A & $\mathrm{A}$ \\
\hline \multicolumn{2}{|c|}{ Sleep } & $\mathrm{N}$ & $\mathrm{N}$ & $\mathrm{N}$ & $\mathrm{N}$ & $\mathrm{N}$ & $\mathrm{N}$ & $\mathrm{N}$ & $\mathrm{N}$ & $\mathrm{N}$ & $\mathrm{N}$ & $\mathrm{N}$ & $\mathrm{N}$ \\
\hline \multirow{3}{*}{ Respiration } & Stimulation & A & $\mathrm{A}$ & A & $\mathrm{A}$ & A & A & A & A & $\mathrm{A}$ & $\mathrm{A}$ & A & $\mathrm{A}$ \\
\hline & Depression & A & $\mathrm{A}$ & A & $\mathrm{A}$ & A & A & A & $\mathrm{A}$ & $\mathrm{A}$ & $\mathrm{A}$ & A & A \\
\hline & Failure & A & $\mathrm{A}$ & A & $\mathrm{A}$ & A & A & A & $\mathrm{A}$ & $\mathrm{A}$ & $\mathrm{A}$ & A & $\mathrm{A}$ \\
\hline \multicolumn{2}{|c|}{ Coma } & A & $\mathrm{A}$ & A & $\mathrm{A}$ & A & A & A & $\mathrm{A}$ & $\mathrm{A}$ & $\mathrm{A}$ & $\mathrm{A}$ & $\mathrm{A}$ \\
\hline \multirow{3}{*}{ Skin color } & Blanching & A & $\mathrm{A}$ & A & $\mathrm{A}$ & A & A & A & $\mathrm{A}$ & $\mathrm{A}$ & $\mathrm{A}$ & A & A \\
\hline & Cyanosis & A & $\mathrm{A}$ & A & $\mathrm{A}$ & A & A & A & $\mathrm{A}$ & $\mathrm{A}$ & $\mathrm{A}$ & A & $\mathrm{A}$ \\
\hline & Vasodilatation & A & $\mathrm{A}$ & A & $\mathrm{A}$ & A & A & A & $\mathrm{A}$ & $\mathrm{A}$ & $\mathrm{A}$ & A & $\mathrm{A}$ \\
\hline \multicolumn{2}{|c|}{ Convulsion } & A & $\mathrm{A}$ & A & $\mathrm{A}$ & A & A & A & $\mathrm{A}$ & $\mathrm{A}$ & $\mathrm{A}$ & A & $\mathrm{A}$ \\
\hline \multicolumn{2}{|c|}{ Arching \& Rolling } & A & $\mathrm{A}$ & A & $\mathrm{A}$ & A & A & A & $\mathrm{A}$ & $\mathrm{A}$ & $\mathrm{A}$ & A & $\mathrm{A}$ \\
\hline \multicolumn{2}{|c|}{ Muscle spasm } & A & $\mathrm{A}$ & A & $\mathrm{A}$ & A & A & A & A & A & $\mathrm{A}$ & A & $\mathrm{A}$ \\
\hline \multicolumn{2}{|c|}{ Tremors } & A & $\mathrm{A}$ & A & A & A & $\mathrm{A}$ & A & A & A & A & A & A \\
\hline \multicolumn{2}{|c|}{ Diarrhea } & A & $\mathrm{A}$ & A & $\mathrm{A}$ & A & A & A & $\mathrm{A}$ & A & $\mathrm{A}$ & A & $\mathrm{A}$ \\
\hline \multicolumn{2}{|c|}{ Morbidity } & A & A & A & $\mathrm{A}$ & A & A & A & A & A & $\mathrm{A}$ & A & $\mathrm{A}$ \\
\hline \multicolumn{2}{|c|}{ Mortality } & $\mathrm{A}$ & $\mathrm{A}$ & $\mathrm{A}$ & $\mathrm{A}$ & $\mathrm{A}$ & $\mathrm{A}$ & A & $\mathrm{A}$ & $\mathrm{A}$ & $\mathrm{A}$ & $\mathrm{A}$ & $\mathrm{A}$ \\
\hline
\end{tabular}

A - Absent and $\mathrm{N}=$ Normal 
Table 4. Protective influence of the four thiosemicarbazone derivatives on the different hematological parameters in Cd-intoxicated rats.

\begin{tabular}{|c|c|c|c|c|c|c|}
\hline \multirow{2}{*}{ Parameter } & \multicolumn{5}{|c|}{ Experimental groups } \\
\cline { 2 - 7 } & \multirow{2}{*}{ Control } & \multicolumn{5}{|c|}{ Cd } \\
\cline { 2 - 6 } & & Vehicle & TSC $_{1}$ & TSC $_{2}$ & TSC $_{3}$ & TSC $_{4}$ \\
\hline WBC $\left({\left.\mathrm{X} 10^{3} \mu 1^{-1}\right)}^{*} 6750+250^{\mathrm{a}}\right.$ & $12650+410^{\mathrm{d}}$ & $10100+250^{\mathrm{c}}$ & $9800+300^{\mathrm{c}}$ & $8250+310^{\mathrm{b}}$ & $7750+250^{\mathrm{b}}$ \\
\hline $\mathrm{RBC}\left(\mathrm{X} 10^{6} \mu 1^{-1}\right)$ & $5.91+0.26^{\mathrm{d}}$ & $4.00+0.15^{\mathrm{a}}$ & $5.25+0.09^{\mathrm{b}}$ & $5.22+0.08^{\mathrm{b}}$ & $5.60+0.16^{\mathrm{c}}$ & $5.72+0.12^{\mathrm{c}}$ \\
\hline $\mathrm{PCV}(\%)$ & $49.15+1.05^{\mathrm{d}}$ & $31.25+1.35^{\mathrm{a}}$ & $38.20+1.90^{\mathrm{b}}$ & $39.20+2.10^{\mathrm{b}}$ & $43.30+1.00^{\mathrm{c}}$ & $43.45+1.05^{\mathrm{c}}$ \\
\hline $\mathrm{Hb}\left(\mathrm{g} \mathrm{dL}^{-1}\right)$ & $14.80+0.30^{\mathrm{e}}$ & $10.90+0.20^{\mathrm{a}}$ & $12.40+0.20^{\mathrm{b}}$ & $12.85+0.15^{\mathrm{b}}$ & $13.40+0.10^{\mathrm{cd}}$ & $14.05+0.25^{\mathrm{d}}$ \\
\hline $\mathrm{MCV}(\mathrm{fL})$ & $77.55+2.35^{\mathrm{b}}$ & $62.80+3.60^{\mathrm{a}}$ & $74.35+2.25^{\mathrm{b}}$ & $74.95+3.25^{\mathrm{b}}$ & $76.60+0.70^{\mathrm{b}}$ & $76.80+1.20^{\mathrm{b}}$ \\
\hline $\mathrm{MCH}(\mathrm{pg})$ & $30.90+1.00^{\mathrm{c}}$ & $20.80+0.10^{\mathrm{a}}$ & $24.80+0.60^{\mathrm{b}}$ & $26.35+0.95^{\mathrm{b}}$ & $26.55+0.55^{\mathrm{b}}$ & $28.55+0.95^{\mathrm{b}}$ \\
\hline MCHC $\left(\mathrm{g} \mathrm{dL}^{-1}\right)$ & $40.75+2.05^{\mathrm{c}}$ & $28.20+1.50^{\mathrm{a}}$ & $32.30+0.10^{\mathrm{b}}$ & $33.95+2.05^{\mathrm{b}}$ & $35.45+0.95^{\mathrm{b}}$ & $36.70+1.80^{\mathrm{b}}$ \\
\hline Platelets $\left(10^{9} \mathrm{~L}^{-1}\right)$ & $8115+300^{\mathrm{c}}$ & $5120+400^{\mathrm{a}}$ & $6360+250^{\mathrm{b}}$ & $6945+200^{\mathrm{b}}$ & $7165+310^{\mathrm{b}}$ & $7590+220^{\mathrm{b}}$ \\
\hline
\end{tabular}

Values are given as mean \pm SEM for 6 rats in each group.

Each value not sharing a common letter superscript is significantly different $(\mathrm{P}<0.05)$.

the other hand, the intoxication of rats with $\mathrm{Cd}$, induced significant reduction $(\mathrm{P}<0.05)$ in the levels of RBCs, PCV, HB, MCV, MCH, MCHC, and Platelets as compared to control groups. However, concurrent treatment with the four TSCs derivatives caused significant restoration in the level of all studied hematological parameters (Table 4).

\section{Effect of the thiosemicarbazone derivatives on} liver function parameters in $\mathrm{Cd}$-intoxicated rats

The liver is prone to damage by various noxious compounds and poisonous products due to biotransformation and storage of numerous xenobiotics that enter the body from various sources. The liver is the primary target organ of Cd toxicity following its ingestion. Determination of enzyme levels such as serum AST, ALT, and ALP is largely used during the assessment of liver damage by $\mathrm{Cd}$ (24). Figure $3 \mathrm{a}, \mathrm{b}$, and $\mathrm{c}$ illustrate the effect of the four TSCs derivatives on some liver function parameters in the control and treated groups against $\mathrm{Cd}$-induced hepatic toxicity in male rats. The recorded results indicated that $\mathrm{Cd}$ intoxication caused a significant increase $(\mathrm{P}<0.05)$ in the activities of AST, ALT, and ALP as compared to the control group. Hepatic dysfunction was the most common regimen-related toxicity reported during $\mathrm{Cd}$ toxicity. It has been reported that $\mathrm{Cd}$ intoxication induced local ischemia in the parenchyma due


Figure 3. The protective influence of the four thiosemicarbazone derivatives on alanine (ALT) (a), aspartate (AST) (b) aminotransaminase, and alkaline phosphatase (ALP) (c) activities in $\mathrm{Cd}$-intoxicated rats. Values are given as mean \pm SEM for 6 rats in each group. Each value not sharing a common letter superscript is significantly different $(\mathrm{P}<0.05)$.

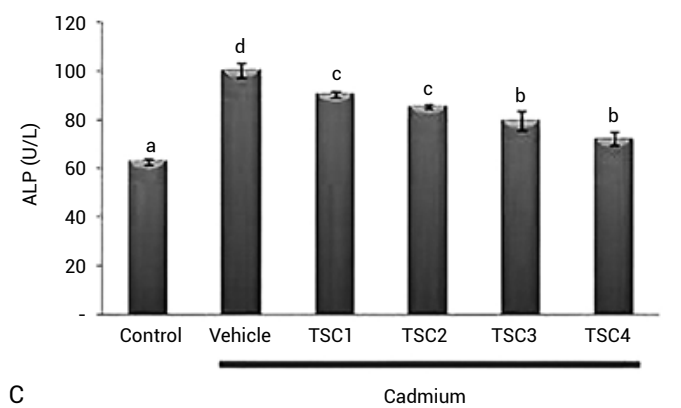


to the extrusion of damaged cells into the capillary lumen (25). Furthermore, Cd hepatotoxicity involved activation of Kupffer cells, which directly damage hepatocytes via the release of a variety of cytotoxic mediators (26). The present study confirmed the findings of (27) and (28), who explained elevation in the serum enzymes AST, ALT, and ALP to direct toxic effect of the $\mathrm{Cd}$, ischemia, and inflammatory injury following exposure of hepatocytes to $\mathrm{Cd}$. Concurrent treatment with TSC1, TSC2, TSC3, and TSC4 significantly $(\mathrm{P}<0.05)$ decreased the activities of the studied enzymes as compared to the $\mathrm{Cd}$-intoxicated group. However, obtained results also show that TSC3 and TSC4 showed significant $(\mathrm{P}<0.05)$ reduction in the activities of AST, ALT, and ALP as compared to TSC1 and TSC2 (Figure $3 \mathrm{a}, \mathrm{b}$ and c). In accordance with the report of Athmouni et al. (27), the administration of four novels TSCs in the present study showed a protective effect against Cd-induced hepatic dysfunction through decreasing the activities of AST, ALT, and ALP, showing its potential to maintain the normal functional status of the liver.

\section{Effect of the thiosemicarbazone derivatives on kidney function parameters in $\mathrm{Cd}$-intoxicated rats}

The primary organs involved in the elimination of $\mathrm{Cd}$ metal are the liver and kidney (24). Data recorded in Figure $4 \mathrm{a}, \mathrm{b}$, and c illustrated that $\mathrm{Cd}$ administration caused a significant increase $(\mathrm{P}<0.05)$ in the levels of creatinine, urea, and uric acids as compared to the control group. During heavy metal toxicity, the kidney is a target organ due to its capability to reabsorb and concentrate divalent ions and metals. Chronic kidney disease (CKD) is a common complication disease that is accompanied by failing organ function leading to the accumulation of a series of compounds (29). In conjunction with the finding of (30), the results of the present study showed that $\mathrm{Cd}$ intoxication induced marked alteration in renal functions as manifested by a significant increase in the kidney function markers, serum creatinine, urea, and uric acid. The increased levels in serum kidney function markers may be due to chronic inflammation, fibrosis, and renal failure (31), which developed due to reabsorption of both the protein-bound (nondiffusible) and complex/ionized (diffusible) forms of heavy metals (8). In addition, the elevation of serum levels of uric acid following $\mathrm{Cd}$ intoxication could confirm the presence of kidney injury caused by the reduction in glomerular filtration rate (GFR) which was confirmed by the histopathological examination of the kidney. Moreover, (32) showed that Cd intoxication induced features of hepatorenal syndrome, including a significant increase in the serum creatinine, and reductions in creatinine clearance, water excretion, and urinary sodium concentration. It has been demonstrated that oxidative stress and mitochondrial damage are among the fundamental molecular mechanisms of Cd nephrotoxicity (33). Meanwhile,
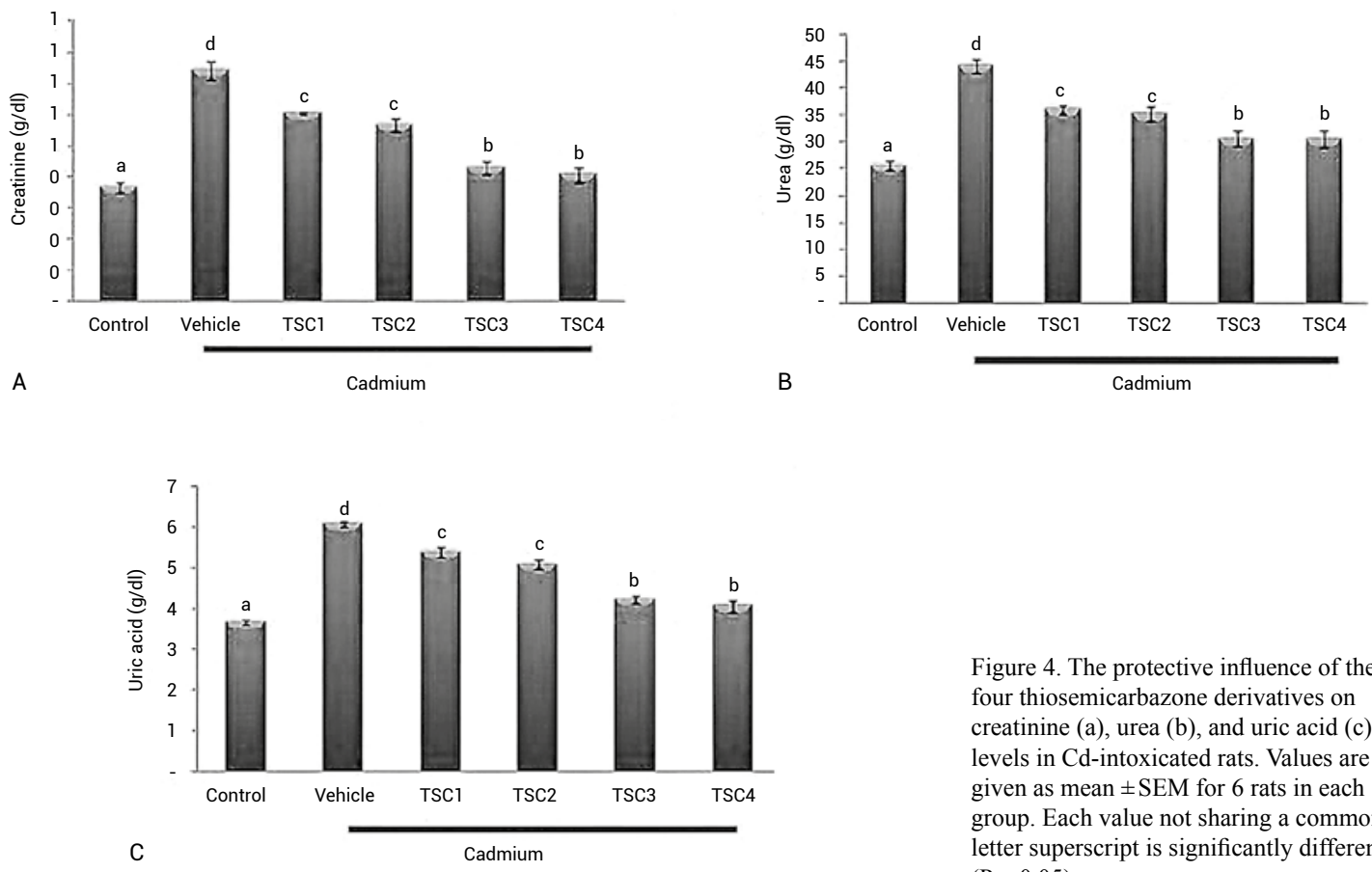

Figure 4. The protective influence of the four thiosemicarbazone derivatives on creatinine (a), urea (b), and uric acid (c) levels in Cd-intoxicated rats. Values are given as mean \pm SEM for 6 rats in each group. Each value not sharing a common letter superscript is significantly different $(\mathrm{P}<0.05)$. 
the possibly enhanced production of the reactive oxygen species could be renal toxic consequently impairing the functional capacity of the kidney (7). The present study showed that treated rats with all studied TSCs derivatives showed a significant decrease in serum creatinine, urea, and uric acid concentrations, which highlight their therapeutic efficacies in alleviating nephrotoxicity induced by $\mathrm{Cd}$.

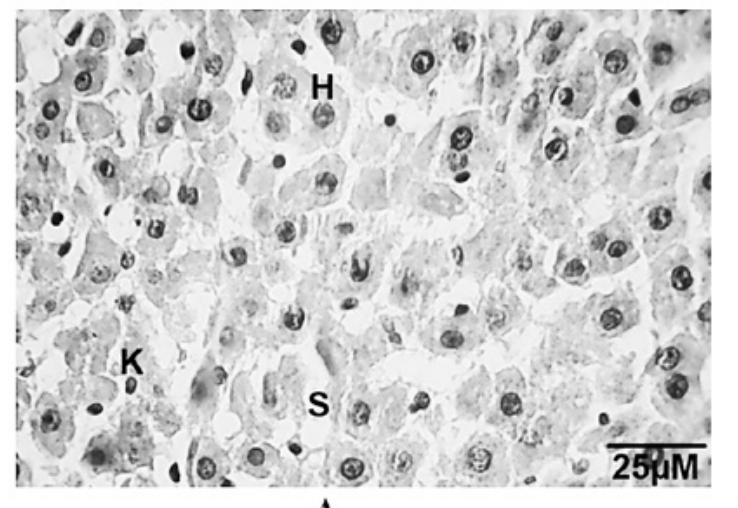

A


E
The present study also affirmed that both $\mathrm{TSC}_{3}$ and $\mathrm{TSC}_{4}$ showed an efficient improvement in liver and kidney function parameters. This improvement may be due to a contributory self-healing mechanism of $\mathrm{TSC}_{3}$ and $\mathrm{TSC}_{4}$ that restoring the liver and kidney structure and function. Histopathological observation of the tissues had directly supported this conclusion (Figure 5 and 6).
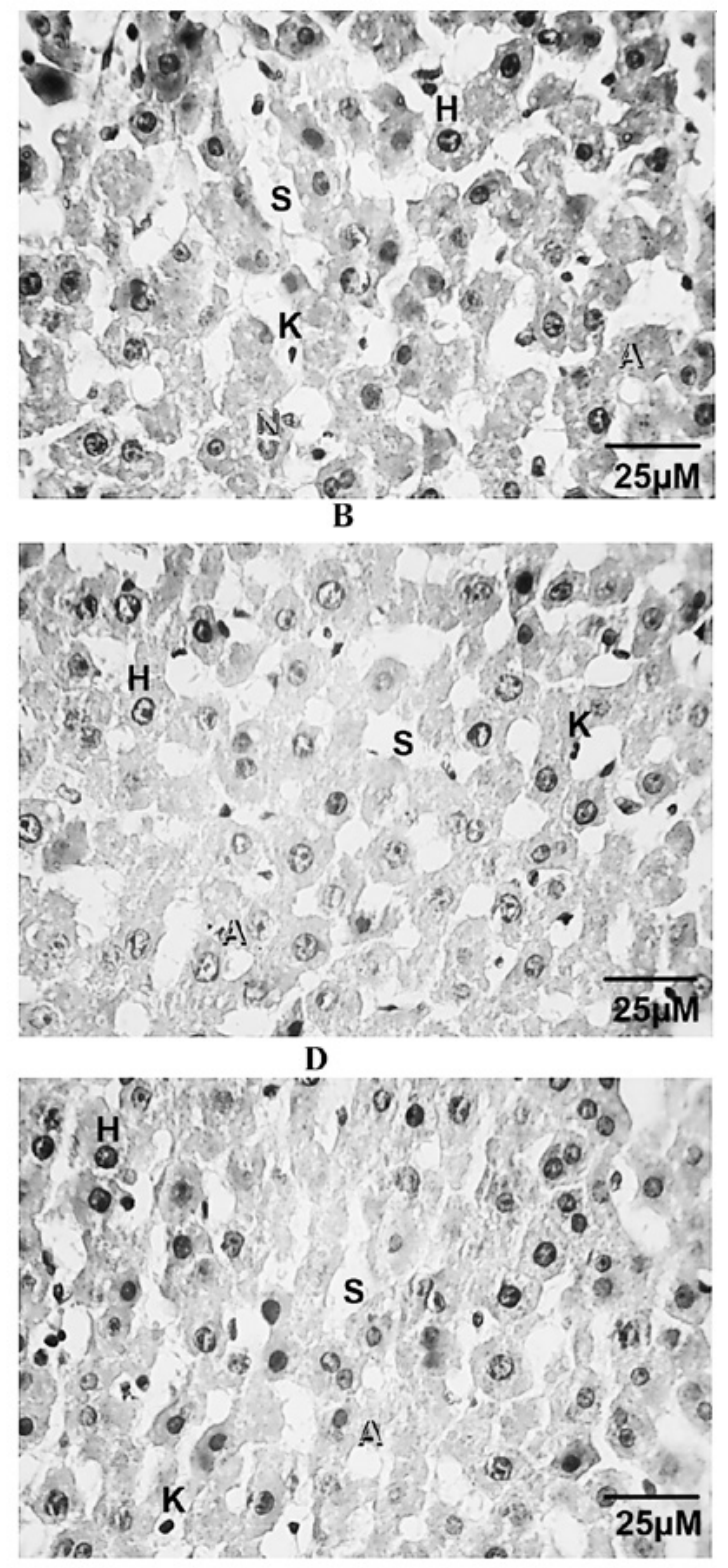

$\mathbf{F}$

Figure 5. Photomicrograph of hematoxylin and eosin-stained liver sections from control (A), Cd (B), TSC1 (C), TSC2 (D) TSC3 (E), and TSC4 (F) treated rats. Histopathological examination of the control rat's liver showed apparently normal histological findings of hepatocytes $(\mathrm{H})$ and blood sinusoids $(\mathrm{S})$ (Figure 5A). On the other hand, an examination of liver sections of Cd-treated rats demonstrated necrosis $(\mathrm{N})$, adipocytes $(\mathrm{A})$, and severe destructive changes in hepatic architecture (Figure 5B). However, an examination of liver sections of TSC1 and TSC2 treated groups showed moderate to mild degenerated changes in hepatocytes and many adipocytes (Figure 5C and D). The liver of TSC3 and TSC4 treated rats demonstrated normal hepatocyte and moderately improved the hepatic architecture (Figure 5E and F). 
Effect of the thiosemicarbazone derivatives on some oxidative parameters in $\mathrm{Cd}$-intoxicated rats

The present investigation served to determine potential correlations between $\mathrm{Cd}$ intoxication and oxidative stress in the liver and kidney of rats. Data recorded in Table 5 showed a significant increase
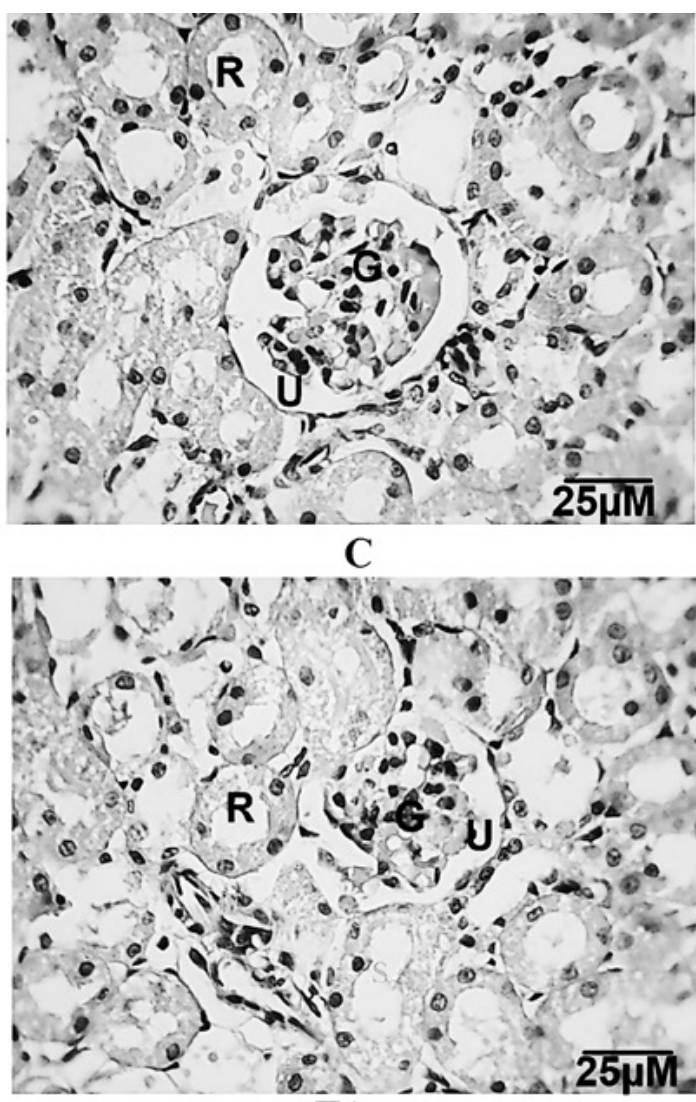

T1

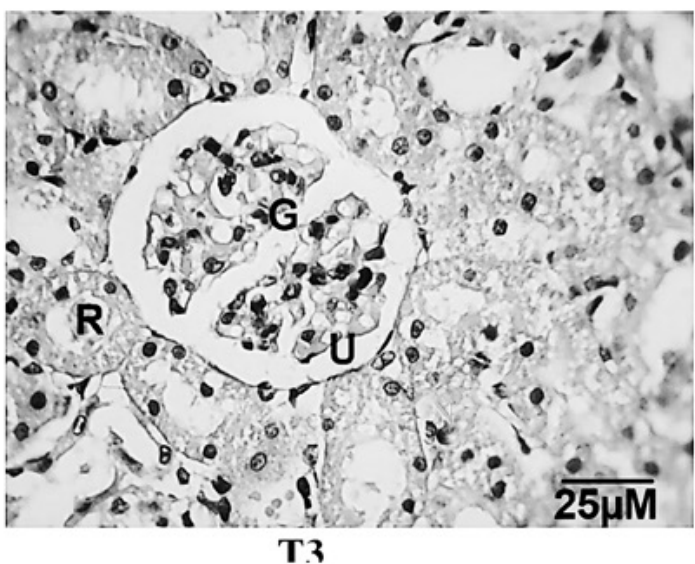

$(\mathrm{P}<0.05)$ in the levels of liver and kidney MDA subsequent to $\mathrm{Cd}$ administration. On the other hand, $\mathrm{Cd}$ intoxication caused a significant decrease $(\mathrm{P}<0.05)$ in the levels of liver and kidney GSH and CAT. It is well known that the critical event in cadmium-induced hepatotoxicity is the impairment of the antioxidant defense system. In conjunction with the
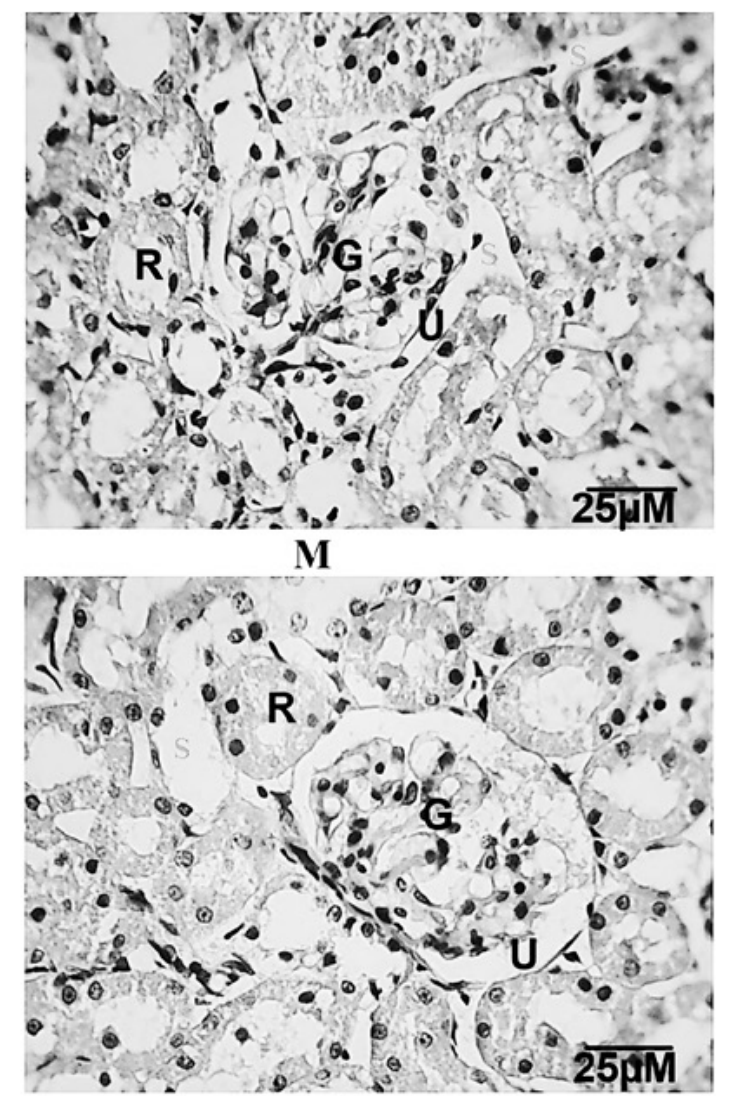

T2

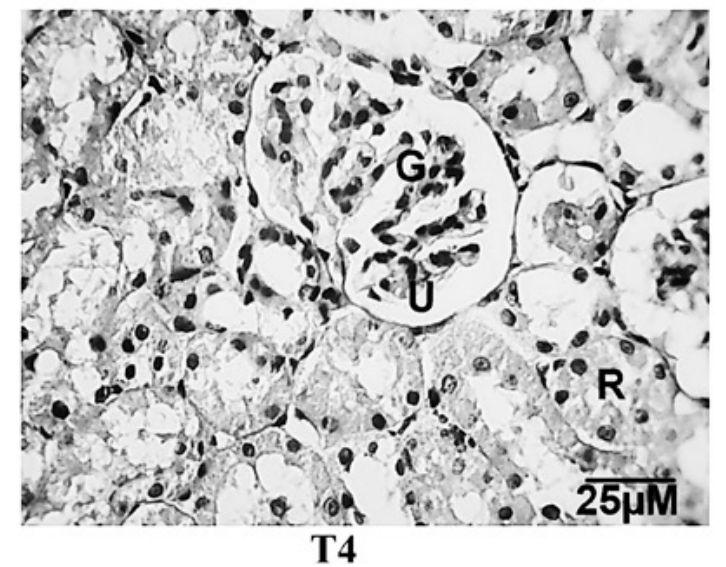

T4

Figure 6. Photomicrograph of hematoxylin and eosin-stained kidney sections from control (A), Cd (B), TSC1 (C), TSC2 (D) TSC3 (E), and TSC4 (F) treated rats. Microscopic examination of the kidney of the control group showed a normal appearance of the tissue where, glomeruli $(\mathrm{G})$ appear as dense tufts of capillaries enclosed in the outer layer of Bowman capsules, urinary space (U), and renal tubules (R) (Figure 6A). The kidney of Cd-treated rats showed severe shrinking and degeneration of glomeruli, degeneration, and necrosis in the epithelial lining of the renal tubules $(\mathrm{N})$, interstitial mononuclear inflammatory cells infiltration $(\mathrm{F})$, and cystic dilatation of the renal tubules (S) (Figure 6B). The kidney of TSC1 and TSC2 treated groups showed mild degeneration in renal tissue architecture, as compared to Cd treated group (Figure 6C and D). Kidney sections of the TSC3 and TSC4 treated group demonstrated healthy renal tissues (Figure 6E and F). 
Table 5. Protective influence of the four thiosemicarbazone derivatives on some oxidative stress parameters in Cd-intoxicated rats.

\begin{tabular}{|c|c|c|c|c|c|c|c|}
\hline \multirow{4}{*}{ Parameter } & & \multicolumn{6}{|c|}{ Experimental groups } \\
\cline { 2 - 8 } & Organ & \multirow{2}{*}{ Control } & \multicolumn{5}{|c|}{ Cd } \\
\cline { 3 - 8 } & & Vehicle & TSC $_{1}$ & TSC $_{2}$ & TSC $_{3}$ & TSC $_{4}$ \\
\hline $\begin{array}{c}\text { MDA } \\
(\text { nmole/g Tissue) }\end{array}$ & Liver & $2.64+0.07^{\mathrm{a}}$ & $5.27+0.20^{\mathrm{d}}$ & $4.64+0.12^{\mathrm{c}}$ & $4.45+0.07^{\mathrm{c}}$ & $3.45+0.20^{\mathrm{b}}$ & $3.14+0.07^{\mathrm{b}}$ \\
\cline { 2 - 8 } & Kidney & $2.72+0.07^{\mathrm{a}}$ & $3.98+0.07^{\mathrm{d}}$ & $3.90+0.04^{\mathrm{c}}$ & $3.78+0.05^{\mathrm{c}}$ & $3.25+0.05^{\mathrm{b}}$ & $3.04+0.14^{\mathrm{b}}$ \\
\hline $\begin{array}{c}\text { GSH } \\
(\mathrm{g} / \mathrm{mg} \text { Tissue) }\end{array}$ & Liver & $11.35+0.06^{\mathrm{d}}$ & $7.93+0.15^{\mathrm{a}}$ & $8.60+0.07^{\mathrm{c}}$ & $8.85+0.08^{\mathrm{c}}$ & $9.46+0.18^{\mathrm{b}}$ & $9.99+0.08^{\mathrm{b}}$ \\
\cline { 2 - 8 } & Kidney & $10.56+0.11^{\mathrm{d}}$ & $6.63+0.03^{\mathrm{a}}$ & $7.72+0.07^{\mathrm{c}}$ & $7.77+0.12^{\mathrm{c}}$ & $9.81+0.16^{\mathrm{b}}$ & $9.91+0.09^{\mathrm{b}}$ \\
\hline $\begin{array}{c}\text { CAT } \\
(\mathrm{U} / \mathrm{g} \text { Tissue) }\end{array}$ & Liver & $7.62+0.07^{\mathrm{e}}$ & $2.14+0.08^{\mathrm{a}}$ & $2.61+0.10^{\mathrm{b}}$ & $2.71+0.04^{\mathrm{b}}$ & $4.45+0.06^{\mathrm{c}}$ & $6.14+0.10^{\mathrm{d}}$ \\
\cline { 2 - 8 } & Kidney & $5.22+0.04^{\mathrm{c}}$ & $1.94+0.10^{\mathrm{a}}$ & $2.23+0.07^{\mathrm{b}}$ & $2.43+0.03^{\mathrm{b}}$ & $3.49+0.12^{\text {cd }}$ & $4.55+0.04^{\mathrm{d}}$ \\
\hline
\end{tabular}

Values are given as mean \pm SEM for 6 rats in each group.

Each value not sharing a common letter superscript is significantly different $(\mathrm{P}<0.05)$.

reports of (34) and (35), data from the present investigation reflects that oxidative stress in the liver and kidney is a common feature of Cd toxicity. One of the highly reactive metabolic products that are produced as the result of a series of reactions due to lipid peroxidation is MDA. In consonance with the report of (34) and (35), the present study showed a significant increase in MDA levels in the liver and kidney following $\mathrm{Cd}$ toxicity in rats which may suggest enhanced lipid peroxidation leading to tissue damage and failure of antioxidant defense mechanisms. It was reported that exposure to $\mathrm{Cd}$ is characterized by the depletion of tissue and circulating non-enzymatic antioxidants including GSH (36). Moreover, the concomitant depletion in the level of GSH with an increment of MDA levels could support the notion that depletion of the liver and kidney GSH after Cd-induced hepatorenal injury is one of the major factors that permit lipid peroxidation and subsequent tissue damage. Inside the living organisms detoxification of cadmium occurs through the formation of Cd-thiol complexes inside the cell which can interpret the reduction in GSH level after Cd intoxication (37). However, a decrease of lipid peroxidation-mediated oxidative stress may be a potential and effective strategy for the prevention and treatment of hepatic failure during $\mathrm{Cd}$ toxicity. The present study confirmed the findings of (38) and (39), who reported that TSCs derivatives significantly decreased MDA and increased GSH levels following $\mathrm{Cd}$ administration suggesting that their therapeutic mechanism may be due to their antioxidant activity. The biological actions of different TSC compounds are based on their ability to chelate metal ions (40). It was reported that the excellent metal ion chelating capacity of the TSC molecule is due to the presence of amide, imine, and thione groups (41). Generally, the position and type of substituent on the TSC backbone have a strong impact on the overall properties and stability, as well as its biological activity. Herein, data recorded suggested that the substituents on TSC molecules had a profound effect on their antioxidant activity in the order of $\mathrm{TSC}_{1}<\mathrm{TSC}_{2}<\mathrm{TSC}_{3}<\mathrm{TSC}_{4}$. It is clear that the $\mathrm{TSC}_{3}$ and $\mathrm{TSC}_{4}$, bearing - ethyl and phenyl substitutions showed the highest antioxidant activity as compared to the remaining compounds. The present study affirmed the report of (42), which reported that compounds containing aromatic or phenolic rings showed the most effective antioxidant activity by donating $\mathrm{H}^{\cdot}$ to the free radicals formed during oxidation (42). Taking into consideration the relation between $\mathrm{Cd}$ toxicity and oxidative stress on one hand, and the relation between $\mathrm{Cd}$ concentration in the tissues and toxicity, on the other hand, the present investigation aimed to evaluate the mechanism of action by which the studied TSCs derivatives perform during $\mathrm{Cd}$ detoxification.

\section{CONCLUSION}

It can be concluded from the aforementioned investigation that the synthesized TSCs derivatives might be acting through two main mechanisms, the $1^{\text {st }}$ one is antioxidant and the $2^{\text {nd }}$ one is chelating therapy. The antioxidant mechanism is already confirmed through the reduction of lipid peroxidation and the improvement of the antioxidant status of the treated rats. Regarding the chelation effect of the synthesized TSCs derivatives can also be confirmed through the significant reduction in the level of $\mathrm{Cd}$ contents in the liver and kidney especially after treatment with $\mathrm{TSC}_{3}$ and $\mathrm{TSC}_{4}$ derivatives.

\section{Conflict of interest}

The authors report no conflicts of interest. 


\section{REFERENCES}

1. Ye X., Qian H., Xu P., Zhu L., Longnecker M.P., Fu H.: Int. J. Hyg. Environ. Health 212, 378 (2009).

2. Luo S., Terciolo C., Bracarense A.P.F.L., Payros D., Pinton P., Oswald I.P.: Environ. Int. 132, 105082 (2019).

3. Batool Z., Agha F., Tabassum S., Batool T.S., Siddiqui R.A., Haider S.: Acta Neurobiol. Exp. (Wars) 79, 169 (2019).

4. Andrade V.M., Aschner M., Marreilha Dos Santos A.P.: Adv. Neurobiol. 18, 227 (2017).

5. Zhang W., Zhi J., CuiY., Zhang F., Habyarimana A.: PLoS One 9, e109 (2014).

6. Steinnes E., Friedland A.J.: Environ. Rev. 14, 169 (2006).

7. Zhuang J., Nie G., Yang F., Dai X., Cao H., Xing C.: Toxicol. In Vitro 61, 104625 (2019).

8. Klaassen C.D., Liu J., Diwan B.A.: Toxicol. Appl. Pharmacol. 238, 215 (2009).

9. Amadi C.N., Offor S.J., Frazzoli C., Orisakwe O.E.: Environ. Sci. Pollut. Res. Int. 26, 18032 (2019).

10. Koduru J.R., Lee K.D.: Food Chem. 150, 1 (2014).

11. Serda M., Kalinowski D.S., Rasko N., Potůčková E., Mrozek-Wilczkiewicz A., et al.: PLoS One 9, el10291 (2014).

12. Emmanuel E.U., Onagbonfeoana E.S., Chinedu N.P., Chibuike A.O., Edith O.C., et al.: J. Appl. Pharma. Sci. 7, 109 (2017).

13. Layachi N., Kechrid Z.: Afr. J. Biotechnol. 11, 16013 (2012).

14. Elslimani F.A., Elmhdwi M.F., Elabbar F., Dakhil O.O.: Der Chemica Sinica 4, 120 (2013).

15. Wong T.S., Hashim Z., Zulkifli R.M., Ismail H.F., Zainol S.N., et al.: Chem. Eng. Trans. 56, 1567 (2017).

16. Coulter P.P.: Am. J. Nurs. 53, 1201 (1953).

17. Ohkawa H., Ohishi N., Yagi K.: Anal. Biochem. 95, 351 (1979).

18. Beutler E., Duron O., Kelly M.B.: J. Lab. Clin. Med. 61, 882 (1963).

19. Aebi H.: Methods Enzymol. 105, 121 (1984).

20. Muthukumar K., Nachiappan V.: Indian J. Biochem. Biophys. 47, 338 (2010).

21. Wu X., Su S., Zhai R., Chen K., Jin T., et al.: Biometals 17, 435 (2004).

22. Vilensky J.A., Redman K.: Ann. Emerg. Med. 41, 378 (2003).
23. Gonick H.C.: Indian J. Med. Res. 128, 335 (2008).

24. Sanjeev S., Bidanchi R.M., Murthy M.K., Gurusubraman M.: Environ. Sci. Pollut. Res. Int. 26, 20631 (2019).

25. Rikans L.E., Yamano T.: J. Biochem. Mol. Toxicol. 14, 110 (2000).

26. Horiguchi H., Harada A., Oguma E., Sato M., Homma Y., et al.: Toxicol. Appl. Pharmacol. 163, 231 (2000).

27. Athmouni K., Belhaj D., El Feki A., Ayadi H.: Int. J. Biol. Macromol. 108, 853 (2018).

28. Mumtaz S., Ali S., Khan R., Andleeb S., Ulhaq M., et al.: Environ. Sci. Pollut. Res. Int. 27, 14087 (2019).

29. Orr S.E., Bridges C.C.: Int. J. Mol. Sci. 18, E1039 (2017).

30. Akinyemi A.J., Onyebueke N., Faboya O.A., Onikanni S.A., Fadaka A., Olayide I.: J. Food Drug Anal. 25, 438 (2017).

31. Sabolić I.: Nephron Physiol. 104, 107 (2006).

32. Mitsumori K., Shibutani M., Sato S., Onodera H., Nakagawa J., et al.: Arch. Toxicol. 72, 545 (1998).

33. Wang L., Wang H., Li J., Chen D., Liu Z.: Arch. Environ. Contam. Toxicol. 61, 500 (2011).

34. Owumi S.E., Dim U.J., Najophe E.S.: Toxicol. Ind. Health 35, 537 (2019).

35. Ansari M.N., Ganaie M.A., Rehman N.U., Alharthy K.M., Khan T.H., et al.: Saudi Pharm. J. 27, 673 (2019).

36. Hossain S.K., Bhattacharya S.: Environ Toxicol. Pharmacol. 22, 298 (2006).

37. Cuypers A., Plusquin M., Remans T., Jozefczak D.: Biometals 23, 927 (2010).

38. Thanh N.D., Giang N.T.K., Quyen T.H., Huong D.T., Toan T.: Eur. J. Med. Chem. 123, 532 (2016).

39. Subhashree G.R., Haribabu J., Saranya S., Yuvaraj P., Anatha Krishnan D., et al.: J. Mol. Struct. 1145, 160 (2017).

40. Rogolino D., Cavazzoni A., Gatti A., Tegoni M., Pelosi G., et al.: Eur. J. Med. Chem. 128, 140 (2017).

41. Lobana T.S., Khanna S., Hundal G., Butcher R.J., Castineiras A.: Polyhedron 28, 3899 (2009).

42. Huyut Z., Beydemir S., Gülçin I.: Biochem. Res. Int. 2017, 10 pages (2017). 
